\title{
EMA advice on the use of NSAIDs for Covid-19
}

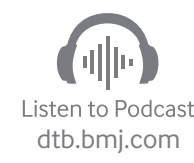

Overview of: European Medicines Agency. EMA gives advice on the use of non-steroidal anti-inflammatories for Covid-19. $E M A / 136850 / 2020$

\section{Key learning points}

- The European Medicines Agency (EMA) has responded to reports questioning whether use of ibuprofen or other NSAIDs could worsen coronavirus disease (Covid-19).

- No scientific evidence has established a link between ibuprofen and worsening of Covid-19.

- The EMA has advised that there is no reason for patients who are taking NSAIDs for chronic diseases to stop taking them.

- Many national treatment guidelines recommend using paracetamol as the first-line option for fever or pain.

The EMA has issued advice on the use of ibuprofen and other NSAIDs in people who have coronavirus disease (Covid-19). ${ }^{1}$

\section{EMA advice}

In response to media reports that have questioned the safety of ibuprofen and other NSAIDs in people who have Covid-19, the EMA has issued a statement clarifying its position. ${ }^{1}$ The document states that there is currently no scientific evidence establishing a link between ibuprofen and worsening of Covid-19. It advises that when treating fever or pain in people with Covid19 , patients and healthcare professionals should take into account the harms and benefits of all available treatment options including paracetamol and NSAIDs. It notes that most EU national treatment guidelines recommend paracetamol as the first-line treatment for fever or pain.

The EMA is monitoring the situation and will review any new information that becomes available. ${ }^{1}$ In 2019, the EMA's Pharmacovigilance Risk Assessment Committee began a review of ibuprofen and ketoprofen following claims that these drugs could worsen chickenpox and some bacterial infections. The summaries of product characteristics for several NSAIDs already include a warning that these drugs may mask the signs or symptoms of a worsening infection.

\section{Context}

Covid-19 is caused by the severe acute respiratory syndrome coronavirus 2 (SARS-CoV-2). Human pathogenic coronaviruses bind to their target cells through angiotensin converting enzyme 2 (ACE2) and the production of ACE2 can be increased by some drugs including ibuprofen. ${ }^{2}$ Researchers writing in The
Lancet Respiratory Medicine have suggested that increased production of ACE2 would facilitate infection with SARS-CoV-2. They hypothesised that ACE2 stimulating drugs may increase the risk of developing severe and fatal Covid-19. However, the researchers commented that this hypothesis requires further study and investigation and that there is no clear evidence of an adverse impact from ibuprofen. ${ }^{3}$

The UK Medicines and Healthcare products Regulatory Agency (MHRA) has reported that there is currently no research into the link between ibuprofen and the likelihood of contracting SARS-CoV-2, or the link between ibuprofen and the worsening of Covid- 19 symptoms. ${ }^{4}$ The MHRA has advised patients to take paracetamol to treat the symptoms of Covid-19, unless paracetamol is not suitable for them. People who have been advised to use ibuprofen by a healthcare professional should not stop taking it.

Fever is an innate natural response to infection that helps to stimulate the immune system. ${ }^{5}$ The increase in body temperature may help to reduce replication of pathogens. It has been suggested that the use of antipyretic drugs to manage fever is associated with worse outcomes in some patients being treated in intensive care units.

The overall balance of harms and benefits of antipyretic treatment of fever in people with Covid-19 is unclear. If treatment of symptoms related to Covid-19 is deemed necessary, paracetamol remains the first-line option provided there are no contraindications to its use. This is in line with guidance issued by the medical director for NHS England who has advised that patients who have confirmed Covid-19 or believe they have Covid-19 should use paracetamol rather than NSAIDs. ${ }^{6}$ The
Commission on Human Medicines and the National Institute for Health and Care Excellence have been asked to clarify the evidence on the effect of NSAIDs in people with Covid-19.

\section{Contributors DTB Team.}

Provenance and peer review Commissioned; internally peer reviewed.

(c) BMJ Publishing Group Limited 2020. No commercial re-use. See rights and permissions. Published by BMJ.

\section{References}

1 European Medicines Agency. EMA gives advice on the use of non-steroidal antiinflammatories for COVID-19 [online]. 2020. Available: https://www.ema.europa.eu/en/ news/ema-gives-advice-use-non-steroidalanti-inflammatories-covid-19 [Accessed 24 March 2020].

2 Fang L, Karakiulakis G, Roth M. Are patients with hypertension and diabetes mellitus at increased risk for COVID-19 infection? Lancet Respir Med 2020. doi:10.1016/S22132600(20)30116-8. [Epub ahead of print: 11 Mar 2020]. Epub ahead of print.

3 Roth M. Ibuprofen and COVID-19 [online]. 2020. Available: https://www.unibas.ch/en/ News-Events/News/Uni-Research/Ibuprofenand-COVID-19-Setting-the-record-straight. html [Accessed 24 March 2020].

4 Medicines and Healthcare products Regulatory Agency. Ibuprofen use and Coronavirus (COVID-19) [online]. 2020. Available: https://www.gov.uk/government/ news/ibuprofen-use-and-covid19coronavirus [Accessed 24 March 2020].

5 Evans SS, Repasky EA, Fisher DT. Fever and the thermal regulation of immunity: the immune system feels the heat. Nat Rev Immunol 2015;15:335-49.

6 Powis S. Message for all clinical staff: antiinflammatory medications [online]. Available: https://www.cas.mhra.gov.uk/ViewandAckno wledgment/ViewAlert.aspx?AlertID=103001 [Accessed 24 March 2020]. 